\title{
MODELLING AND EXPERIMENTAL STUDY OF ENERGY FEED SUSPENSION SYSTEM FOR ELECTRIC VEHICLE
}

\author{
Xiumei Wang ${ }^{1}$ \\ ${ }^{1}$ Vehicle Engineering (rail transit) College, Changzhou Vocational Institute of Mechatronic Technology, Changzhou \\ 213164, Jiangsu, China \\ Email: $\underline{\text { wxiumeikk1@163.com }}$
}

\begin{abstract}
In order to solve the deterioration of the contradiction between ride comfort and handling stability of wheel-side-driven electric vehicle, the torque control of wheel-driven electric vehicle is studied, the influence of vertical excitation of wheel-driven motor on power performance and energy-feeding characteristics of electric vehicle is analyzed, and the energy-feeding law and characteristics of energy-feeding suspension are discussed. The effective methods that can improve the safety, relaxation, and energy-feeding characteristics of wheel-driven electric vehicle through the control of electromagnetic active suspension are proposed. Through the suspension simulation model and energy recovery simulation model, under the guidance of sliding mode control theory and Drosophila optimization algorithm theory, a control algorithm with excellent control effect is designed for semi-active suspension system design, and the effectiveness of the algorithm is verified by simulation analysis. The simulation model is built by using the input signal of various working conditions as the road input, and the simulation results of the control algorithm are compared with other control algorithms. The results show that the designed control algorithm can effectively improve the vibration reduction effect of suspension compared with other control algorithms. At the same time, the energy recovery efficiency of the energy-fed damper will be investigated through the simulation experiment of the energy-fed damper. Therefore, the study can provide theoretical basis and technical support for the development of wheel-side-drive electric vehicles with independent intellectual property rights.
\end{abstract}

Keywords: Wheel-Side Drive; Energy-Fed Suspension; Electric Vehicle; Energy-Fed Device.

\section{Introduction}

With the German Benz design and manufacture of the world's first three-wheeled car with a gasoline internal combustion engine, the car began to change human life. In the past 50 years, the automobile industry has developed rapidly and a great deal of technology has been innovated. Gradually, automobile has become one of the most important means of transportation in today's society. In recent years, with the rapid growth of automobile production and ownership, human beings are facing severe challenges of energy, environment and climate. New energy vehicles represented by electric vehicles are the best choice to achieve sustainable transportation development [1]. Electric vehicles have attracted much attention due to their advantages of zero emission (or ultra-low emission) in the use process, diversification and efficiency of energy utilization, and easy to realize intelligent control. In recent years, electric vehicles have shown a trend of accelerated development.

Suspension system is an important part of modern automobiles. One of its main tasks is to attenuate the spring-loaded mass vibration caused by uneven road surface and ensure the ride comfort of automobiles. However, in traditional suspension system, this part of vibration energy is usually dissipated by damper in the form of heat. If this part of energy can be effectively recycled and utilized, a new way of vehicle energy saving can be found. On the other hand, the suspension system also bears the responsibility of transferring all forces and moments between the wheel and the body, and ensuring that the vehicle has ideal motion characteristics when the load changes. Its performance directly affects the ride comfort and handling stability of the vehicle.

\section{Literature Review}

The first problem to be solved for energy-fed suspension is the way to recover the vibration energy of suspension, that is, the design of energyfed damped adjustable shock absorber. In 2015, Bello et al. discussed the energy consumption and vibration isolation performance of the electromechanical suspension system based on the establishment of the dynamic equation of the suspension system. Based on the numerical simulation and experimental results, a contour 
diagram for evaluating the performance of the feedback gain axis was proposed [2]. In 2016, Choi et al. proposed gain settings to improve the performance of each vehicle, which were verified by shaking table test.

The simulation and experimental results show that the active suspension system can solve the compatibility between vibration isolation and energy saving [3]. In 2015, Xie and Wang presented the realtime control characteristics of electrorheological (ER) suspension system by considering the sampling rate of electronic control unit (ECU) of vehicle system. A quarter of real-time vehicle control system consisting of spring mass, spring, tire and cylindrical ER damper (shock absorber) was established [4]. In 2016, Xiao and Jing adopted the fuzzy control algorithm in the controller design, which improved the robustness of the system to the quality change and the sliding surface arrival time. Then, the controller of the ER suspension system of a quarter of the vehicle manufactured was realized experimentally [5]. In 2015, Abdullah et al. proposed an effective numerical algorithm for kinematics analysis of standard McPherson suspension system.

The kinematics analysis of suspension mechanism was carried out based on Cartesian coordinates of some defining points in connecting rods and motion joints [6]. In 2015, Huang et al. proposed that the change of stiffness concept adopted reverse drive, which effectively transferred the energy between the vertical traditional pillar and the horizontal vibration control mass, thus improving the energy dissipation of the overall suspension [7]. In 2018, Wei et al. established the lateral dynamic model of the system by using the bicycle model. The accompanying rolling dynamics was studied and validated by experimental data [8].

The simulation results show that the roll response of the variable stiffness suspension system is increased by more than $50 \%$ compared with the traditional constant stiffness suspension system.

\section{Method}

Additional dynamic vibration absorption system on spring-loaded mass supported by linear suspension is one of the basic passive vibration control methods, which helps to improve the vibration characteristics of the vehicle and thus improve its comfort. The appearance of hub motor makes the non-spring load mass of suspension system increase obviously, which has a certain influence on the vibration characteristics of suspension system. At the same time, the vibration problem of hub motor cannot be ignored and too much vibration for a long time will also have a certain impact on the motor itself. In other words, the vibration of non-spring mass of suspension system also needs to be controlled in an appropriate range.

The whole vehicle suspension system is simplified to $1 / 4$ linear suspension system. Its dynamic model consists of two mass blocks and their stiffness and damping. The body mass is springloaded mass, and the hub motor and wheel are nonspring-loaded mass, as shown in Figure 1.

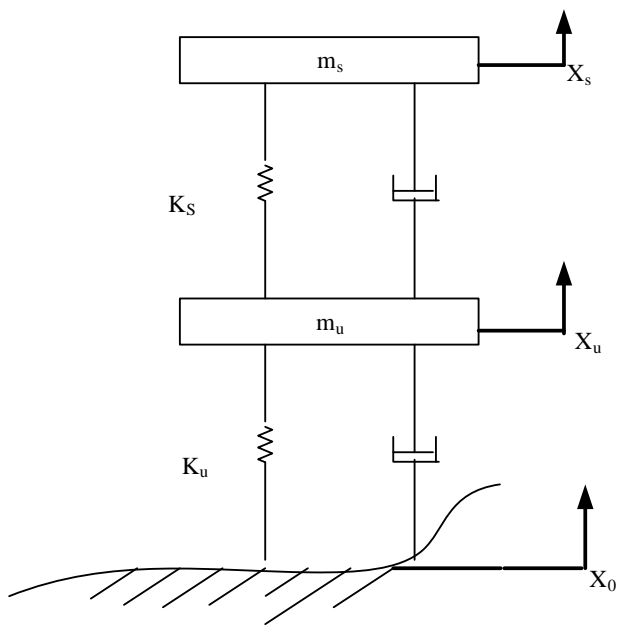

Figure 1: Dynamic model of 1/4 linear suspension system

According to Newton's second law, the differential equation of vibration is:

$$
\left\{\begin{array}{c}
\mathrm{m}_{\mathrm{s}} \ddot{\mathrm{x}}_{\mathrm{s}}+\mathrm{c}_{\mathrm{s}}\left(\dot{\mathrm{x}}_{\mathrm{s}}-\dot{\mathrm{x}}_{\mathrm{u}}\right)+\mathrm{k}_{\mathrm{s}}\left(\mathrm{x}_{\mathrm{s}}-\mathrm{x}_{\mathrm{u}}\right)=\mathrm{O} \\
\mathrm{m}_{\mathrm{u}} \ddot{\mathrm{x}}_{\mathrm{u}}+\mathrm{c}_{\mathrm{s}}\left(\dot{\mathrm{x}}_{\mathrm{u}}-\dot{\mathrm{x}}_{\mathrm{s}}\right)+\mathrm{k}_{\mathrm{s}}\left(\mathrm{x}_{\mathrm{u}}-\mathrm{x}_{\mathrm{s}}\right)+\mathrm{c}_{\mathrm{u}}\left(\dot{\mathrm{x}}_{\mathrm{u}}-\dot{\mathrm{x}}_{\mathrm{o}}\right)+\mathrm{k}_{\mathrm{u}}\left(\mathrm{x}_{\mathrm{u}}-\mathrm{x}_{\mathrm{o}}\right)=\mathrm{O}
\end{array}\right.
$$

In the formula, $\mathrm{m}_{\mathrm{s}}$ and $\mathrm{m}_{\mathrm{u}}$ are spring-loaded mass and non-spring-loaded mass, respectively; $\mathrm{k}_{\mathrm{s}}$ and $\mathrm{k}_{\mathrm{u}}$ are suspension stiffness and tire stiffness, respectively; $c_{s}$ and $c_{u}$ are suspension damping and tire damping coefficient, respectively; $\mathrm{x}_{\mathrm{s}}$ and $\mathrm{x}_{\mathrm{u}}$ are spring-loaded mass displacement and non-springloaded mass displacement, respectively; $\mathrm{x}_{0}$ is road displacement excitation.

The parameters are shown in Table 1.
Table 1. Passive vibration control of electric vehicle linear suspension system

\begin{tabular}{|c|c|}
\hline Parameter & Value \\
\hline $\mathrm{m}_{\mathrm{s}}$ & $310 \mathrm{~kg}$ \\
\hline $\mathrm{k}_{\mathrm{s}}$ & $19600 \mathrm{~N} / \mathrm{m}$ \\
\hline $\mathrm{c}_{\mathrm{s}}$ & $1695 \mathrm{NS} / \mathrm{m}$ \\
\hline $\mathrm{m}_{\mathrm{u}}$ & $55 \mathrm{~kg}$ \\
\hline $\mathrm{k}_{\mathrm{u}}$ & $200000 \mathrm{~N} / \mathrm{m}$ \\
\hline $\mathrm{c}_{\mathrm{u}}$ & $375 \mathrm{NS} / \mathrm{m}$ \\
\hline
\end{tabular}


The amplitude-frequency response curve and the average vibration energy-frequency curve of the suspension system are shown in Figure 2 and Figure 3 . It can be seen from the figure that the amplitude and average vibration energy of spring-loaded mass and non-spring-loaded mass reach the maximum near their natural frequencies; influenced by springloaded mass, there is a small peak near the natural frequencies of spring-loaded mass and average vibration energy; with the increase of vehicle speed, the amplitude of spring-loaded mass becomes smaller and smaller, and the average vibration energy tends to be very small fixed value. That is to say, with the increase of vehicle speed, the frequency of road surface harmonic excitation becomes larger and larger, while the vibration of spring-loaded mass becomes smaller and smaller when the excitation frequency is larger than its natural frequency. Most of the vibration energy generated by simple harmonic excitation is absorbed and dissipated by suspension, that is, linear suspension has good suppression effect on high-order vibration of springloaded mass.

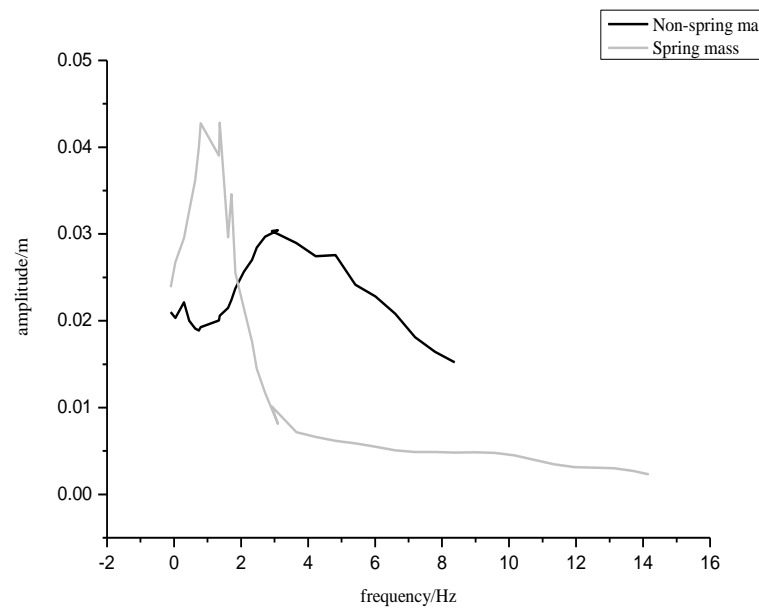

Figure 2: Amplitude-Frequency response curve of linear suspension

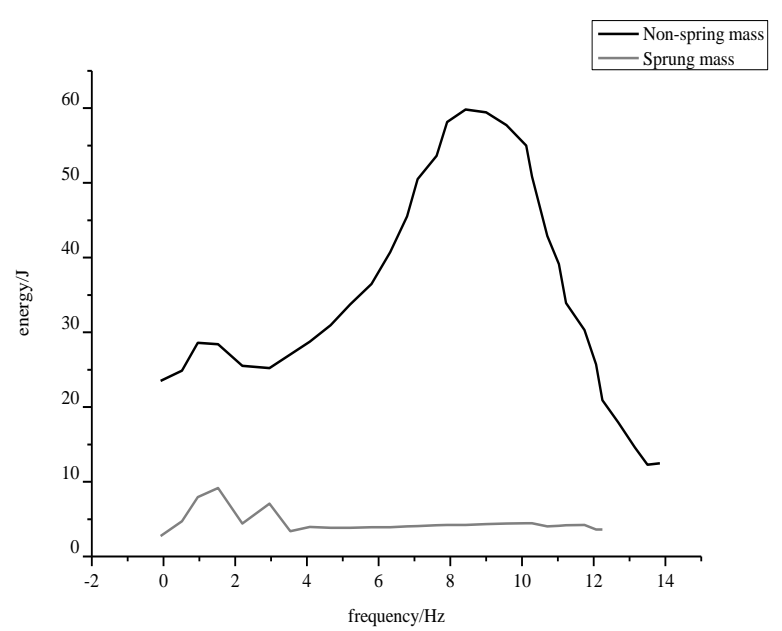

Figure 3: Average vibration energy-frequency curve of linear suspension system

\section{Results and Discussion}

\subsection{Structural design of energy-fed built-in permanent magnet ring magneto- rheological (MR) damper}

MR damper is an intelligent damper based on variable damping coefficient of MR fluids. Its working principle is to change the fluidity of MR fluids by changing the magnitude of the applied magnetic field, so as to achieve the purpose of changing the damping force. Traditional MR dampers only provide external magnetic field by electromagnetic coils, which will cause problems of fault safety and MR fluid static settlement. These problems can be alleviated to some extent by adding permanent magnet ring to MR damper. The external magnetic field of the built-in permanent magnet ring MR damper is provided by the permanent magnet ring and the electromagnetic coil. Therefore, the traditional MR damper structure cannot meet the working requirements of the new MR damper, so it is necessary to redesign the new MR damper structure. At the same time, in order to maximize the recovery of energy, on the premise of convenient installation, energy-fed dampers need to be selected.

The structure diagram of the built-in permanent magnet ring MR damper is shown in Figure 4. The damper consists of upper and lower piston rods, Ishaped piston heads, permanent magnet rings, electromagnetic coils and working cylinders. The working cylinder is filled with MR fluids and installed with pistons; piston rods are connected at both ends of the I-shaped piston head, and permanent magnet rings, electromagnetic coils and epoxy resin are arranged successively from inside to outside of the piston head; a damping passage through which MR fluids flow is arranged between the outside of the piston and the inner wall of the working cylinder. When the car is running, the piston moves up and down in the working cylinder, forcing the MR fluids to move up and internal flow generates damping force.

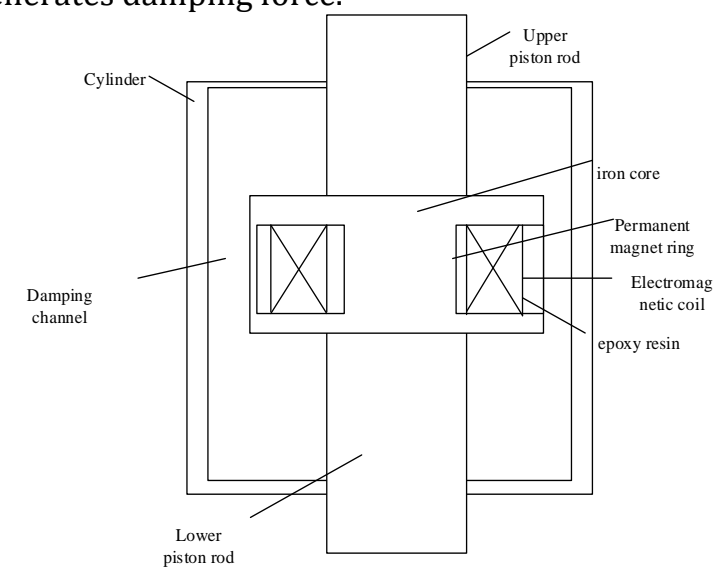

Figure 4: Structural schematic diagram of built-in permanent magnet ring MR damper 
The magnetic field in the damper channel is provided by permanent magnet ring and electromagnetic coil. Its working principle is to control the magnitude and direction of the current of the electromagnetic coil, so that the magnetic field produced by the coil and the magnetic field due to the permanent magnet ring work together, so as to change the magnetic field intensity in the damping channel and achieve the purpose of adjusting the damping force. According to the above working principle, the working modes of the damper can be divided into three types: strengthening mode, weakening mode and permanent magnet ring working mode.

The damper designed is based on the traditional two-bar single-cylinder damper, and its key dimensions are obtained. The range of damping force provided by a certain type of automobile damper is shown in Table 2.

Table 2. Damping force range of a car damper

\begin{tabular}{|l|l|l|l|}
\hline $\begin{array}{l}\text { Piston relative } \\
\text { velocity(m/s) }\end{array}$ & 0.165 & 0.33 & 0.572 \\
\hline damping force(N) & 279.4 & 589.6 & 1100 \\
\hline
\end{tabular}

Through analysis and comparison, considering the design requirements and later test requirements, the ball screw type is adopted as the structural scheme of the energy-fed damper.

\subsection{Modeling of feed-in permanent magnet ring MR damper}

Establishing the mechanical model of the energyfed built-in permanent magnet ring MR damper is the premise and foundation for the research of the energy-fed semi-active suspension.

Therefore, it is of great significance to establish the correct mechanical model of the energy-fed semi-active suspension.

The energy-fed damper designed includes two parts: the built-in permanent magnet ring MR damper and the energy-fed device.

In order to establish the mechanical model of the designed damper, the mechanical model of MR damper and the mechanical model of energy-feeding device can be established, respectively, and then the mechanical model of the energy-feeding built-in permanent magnet ring MR damper can be obtained.

At the same time, in order to study the energy recovery efficiency of the damper, the theoretical model of energy collection of the energy-fed damper will be established according to the structural characteristics of the damper.

For permanent magnets, there are two physical models: the equivalent magnetic charge model and the equivalent current model.

Scalar magnetic potential method and vector magnetic potential method are usually used in calculating the space magnetic field intensity of permanent magnets.

Because the calculation process of vector magnetic potential method is complex, scalar magnetic potential method will be used to calculate the magnetic induction intensity of permanent magnet in the damping channel.

By calculating the magnetic induction intensity of the designed permanent magnet ring in the damping channel, the designed permanent magnet ring can be regarded as the difference between two solid permanent magnets with different diameters.

Therefore, the magnetic induction intensity of two permanent magnets in the damping channel can be calculated separately, and then the difference between them can be calculated.

In order to obtain the magnetic induction strength of permanent magnet at any point in the damping channel, a cylindrical coordinate system can be established with the bottom of the permanent magnet in the XOY plane and the bottom circle in the origin as shown in Figure 5.

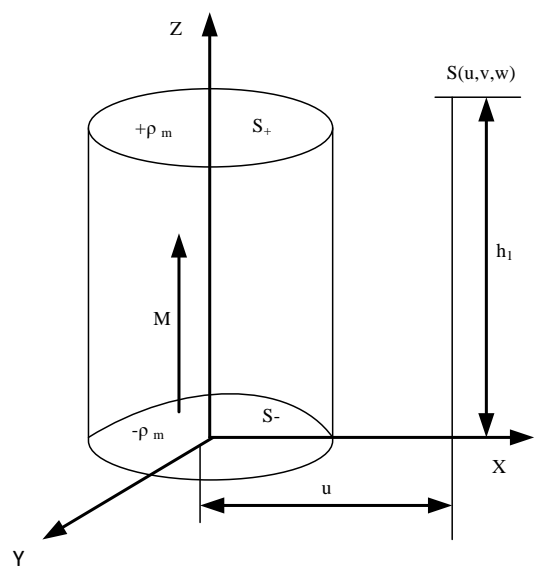

Figure 5: Permanent magnet coordinate sketches

Considering that the permanent magnet is axially homogeneous, there is only surface magnetic charge on the upper and lower surfaces of the permanent magnet, no body magnetic charge.

Therefore, from the equivalent magnetic charge model, the scalar magnetic potential of any point $S$ in the outer space of the permanent magnet is as follows:

$$
\phi=\frac{1}{4} \oint_{\mathrm{s}} \frac{\rho_{\mathrm{m}}}{\mathrm{r}} \mathrm{ds}
$$

By calculating the divergence of $\phi_{\mathrm{m}}$, the magnetic field strength $\mathrm{H}^{\prime}$, i.e. the magnetic field strength $\mathrm{H}^{\prime}$, can be obtained.

$$
\mathrm{H}^{\prime}=-\nabla \bullet \phi_{\mathrm{m}}
$$

Substitute Formula (2) into (3), and then there is:

$$
\begin{aligned}
& \mathrm{H}^{\prime}=-\oint_{\mathrm{s}} \frac{\rho_{\mathrm{m}}}{4 \pi} \bullet \nabla \cdot \frac{1}{\mathrm{r}^{\prime}} \mathrm{ds} \\
& \mathrm{p}_{\mathrm{m}}=\mathrm{M} \cdot \mathrm{e} .
\end{aligned}
$$


$\mathrm{M}$ is the magnetization intensity of permanent magnet; $r^{\prime}$ is the radius of permanent magnet; $S$ is the side surface of permanent magnet cylinder; e is the normal unit vector of external surface of permanent magnet; $\nabla$ is the divergence factor; $\mathrm{p}_{\mathrm{m}}$ is the surface density of magnetic charge.

\subsection{Control algorithms of semi-active suspension system with feed-in permanent magnet ring MR damper}

Generally, the simplified models of semi-active suspension include seven-degree-of-freedom (7DOF) vehicle model, four-degree-of-freedom (4DOF) vehicle model and two-degree-of-freedom (2DOF) $1 / 4$ vehicle body model. The 2 -DOF $1 / 4$ car body model is taken as the research object.

According to the structure characteristics and working principle of suspension, a simplified physical model of 2-DOF $1 / 4$ car body can be established as shown in Figure 6.

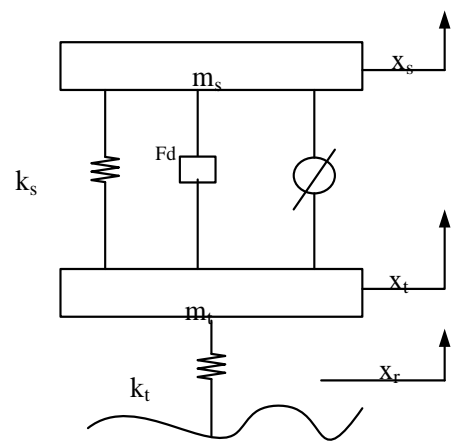

Figure 6: Simplified physical model of 1/4 car body

Based on the simplified physical model, a 2-DOF $1 / 4$ vehicle body mechanical model is established, which is the basis for the research and simulation of control algorithm of semi-active suspension system.

From the simplified physical model of Figure 6, the dynamic equation of the car body is obtained as follows:

$$
\begin{aligned}
& \mathrm{m}_{\mathrm{s}} \ddot{\mathrm{x}}_{\mathrm{s}}+\mathrm{k}_{\mathrm{s}}\left(\mathrm{x}_{\mathrm{s}}-\mathrm{x}_{\mathrm{t}}\right)=-\mathrm{F}_{\mathrm{d}} \\
& \mathrm{m}_{\mathrm{t}} \ddot{\mathrm{x}}_{\mathrm{t}}+\mathrm{k}_{\mathrm{s}}\left(\mathrm{x}_{\mathrm{t}}-\mathrm{x}_{\mathrm{s}}\right)+\mathrm{k}_{\mathrm{t}}\left(\mathrm{x}_{\mathrm{t}}-\mathrm{x}_{\mathrm{r}}\right)=\mathrm{F}_{\mathrm{d}}
\end{aligned}
$$

In the above formulas, $m_{s}$ is $1 / 4$ vehicle mass; $m_{t}$ is non-spring mass; $\mathrm{x}_{\mathrm{s}}$ is body displacement; $\mathrm{xt}_{\mathrm{t}}$ is non-spring mass displacement; $\mathrm{x}_{\mathrm{r}}$ is road disturbance input; $\mathrm{k}_{\mathrm{s}}$ is passive suspension stiffness coefficient; $\mathrm{kt}$ is tire stiffness coefficient; and $\mathrm{F}_{\mathrm{d}}$ is damping force of designed damper.

The designed damper force consists of the damper force of the built-in permanent magnet ring MR damper and the damper force provided by the energy feed device. Among them, the designed damper force mainly includes shear damper force and valve damper force, in which the valve damper force is much larger than the shear damper force.

\subsection{Damping characteristic test of energy-fed built-in permanent magnet ring MR damper}

In order to test whether the damper designed can meet the requirements of automobile suspension, it is necessary to carry out damping characteristic test.

The platform of electro-hydraulic servo vehicle suspension test system is developed by Changchun Kexin Test Instrument Co., Ltd.

The test system platform consists of hardware system and software system.

The hardware system consists of platform frame, excitation generator, load sensor, displacement sensor, controller, special industrial control computer and external water-cooling device.

The test scheme is as follows: Determine the stroke of the damper: compress and stretch the piston to the limit position respectively to detect the maximum stroke of the damper; install the damper specimen: the damper designed is a two-bar singlebarrel structure, and the clamp used in the electrohydraulic servo vehicle suspension test system platform cannot complete the installation, so it needs to redesign and install the fixture.

After redesigning and installing the fixture, the lower piston rod of the damper can be connected with the adjusting locking device of the actuator. The cylinder of the damper is fixed by the designed fixture and the cross beam of the test platform, and the upper piston rod is perforated through the center hole of the cross beam. So far, the damper specimen installation has been completed.

Test parameters: The input excitation signals are sinusoidal waves with amplitudes of $10 \mathrm{~mm}, 15 \mathrm{~mm}$ and $20 \mathrm{~mm}$ and frequencies of $0.5 \mathrm{HZ}$, and the currents of $-0.5 \mathrm{~A}, 0 \mathrm{~A}, 0.5 \mathrm{~A}$ and $1 \mathrm{~A}$ are input by electromagnetic coils respectively. Tensile and compressive tests of dampers are carried out under the above conditions. The number of test cycles is 10 , and test data and load-displacement diagrams are recorded.

In order to test the reliability of the designed built-in permanent magnet ring MR damper and whether it can meet the application requirements of automobile suspension system, the test results are analyzed based on the above test curves. The results show that: first, under the same frequency and different amplitude of sinusoidal excitation signal, when the electromagnetic coil passes through $0 \mathrm{~A}$ current, the designed damper can still output a certain amount of damping force; second, under the condition of sinusoidal excitation signal with the same amplitude and frequency, as the input current of the electromagnetic coil increases, the output damping force of the damper becomes larger and 
larger, and the area surrounded by the indicator diagram of the damper becomes larger and larger, that is, the ability of the damper to dissipate vibration energy becomes stronger and stronger, and the effect of vibration reduction is good.

\section{Conclusion}

The comprehensive control of comfort, safety and energy-saving of wheel-side-driven electric vehicles is studied in depth.

The main contents and achievements are as follows: first, based on the traditional MR damper and energy-fed damper, an energy-fed built-in permanent magnet ring MR damper is designed, which to a certain extent alleviates the fault safety of traditional MR dampers and static settlement of MR fluid, and achieves the purpose of energy recovery.

Second, based on the theory of electromagnetics, the mechanical model of the built-in permanent magnet ring MR damper is established. Through the dynamic analysis of ball screw, the mechanical model of the energy-feeding device is established. On this basis, the mechanical model of the built-in permanent magnet ring MR damper is established. Meanwhile, combined with the structural characteristics of the energy-fed damper, the energy recovery model is established.

Third, aiming at the mutual coupling and restriction of ride comfort, safety and energy saving of wheel-side-driven electric vehicles, a multiobjective suspension mode and its switching strategy are proposed. By judging the basic driving conditions of vehicles, the suspension can work effectively in different working modes, so as to give full play to the advantages of energy-fed active suspension in vehicle dynamic performance improvement and vibration energy recovery, and improve the comprehensive performance of energyfed suspension.

\section{References}

[1] Nguyen, M. Q., Jr, J. M. G. D. S., Sename, O. (2015). A state feedback input constrained control design for a 4-semi-active damper suspension system: a quasi-LPV approach. If ac Papers online, 48(14), 259-264.

[2] Bello, M. M., Akramin Shafie, A., Khan, R. (2015). Active Vehicle Suspension Control Using Full State-Feedback Controller. Advanced Materials Research, 1115, 6.

[3] Choi, H. D., Ahn, C. K., Lim, M. T. (2016). Dynamic output-feedback $\mathrm{H} \infty$ control for active halfvehicle suspension systems with time-varying input delay. International Journal of Control Automation \& Systems, 14(1), 59-68.

[4] Xie, X. D., Wang, Q. (2015). Energy harvesting from a vehicle suspension system. Energy, 86, 385-392.

[5] Xiao, Z., Jing, X. (2016). Frequency-Domain Analysis and Design of Linear Feedback of Nonlinear Systems and Applications in Vehicle Suspensions. IEEE/ASME Transactions on Mechatronics, 21(1), 506-517.

[6] Abdullah, M. A., Jamil, J. F., Muhammad, N. S. Energy regenerative suspension test for EEV and hybrid vehicle. 2015, 100, 012018.

[7] Huang, B., Hsieh, C. Y., Golnaraghi, F. (2015). Development and optimization of an energyregenerative suspension system under stochastic road excitation. Journal of Sound \& Vibration, 357, 16-34.

[8] Wei, C., Ke, Z., Yue, C. (2018). A new method of static output-feedback $\mathrm{H} \infty$ controller design for 5 DOF vehicle active suspension system. Journal of the Brazilian Society of Mechanical Sciences \& Engineering, 40(3), 132. 